\title{
Finescale Planktonic Vertical Structure: Horizontal Extent and the Controlling Physical Processes Layered Organization in the Coastal Ocean (LOCO) DRI
}

\author{
Timothy J. Cowles \\ College of Oceanic and Atmospheric Sciences \\ 104 Oceanography Admin Bldg \\ Oregon State University \\ Corvallis, OR 97331-5503 \\ phone: (541) 737-3966 fax: (541) 737-2064 email: tjc@coas.oregonstate.edu \\ Grant Number N00014-04-1-0277 \\ http://argon.oce.orst.edu/biooptics/projects.htm
}

\section{LONG-TERM GOALS}

Our long-term goal is to quantify the interactions between small-scale biological and physical processes within the upper ocean. Our work within the Layered Organization in the Coastal Ocean (LOCO) DRI examines specific scientific questions that relate the distribution and variability in sub$1 \mathrm{~m}$ scale bio-optical properties with coincident vertical and horizontal scales of physical properties.

\section{OBJECTIVES}

Observations in different ocean areas have confirmed the presence of persistent, small-scale local maxima in the concentrations of nutrients, phytoplankton, and zooplankton. These persistent features result from complex linkages between physical forcing and gradients in the distribution of biological properties. Therefore, our goals within the LOCO DRI are to

- quantify the linkage these physical processes and the steep vertical gradients in biological properties within "thin layers",

- develop a more detailed understanding of the time scales and horizontal spatial scales over which these features persist, and

- evaluate the relative importance of vertical and horizontal processes in establishing planktonic distribution patterns.

\section{APPROACH}

Since completing the LOCO field experiments in 2005 and 2006, our efforts during the past year have focused on the analysis of the extensive data sets obtained in Monterey Bay. During the field experiments, our component investigated the bio/physical linkages in the upper water column by conducting high-resolution vertical profiles of hydrographic, bio-optical, and bio-acoustical properties in conjunction with detailed horizontal mapping of layered properties by other investigators within the LOCO program. We used the multiple instruments on our free-fall profiling system (CTD, ac-9s, 


\section{Report Documentation Page}

Form Approved

OMB No. 0704-0188

Public reporting burden for the collection of information is estimated to average 1 hour per response, including the time for reviewing instructions, searching existing data sources, gathering and maintaining the data needed, and completing and reviewing the collection of information. Send comments regarding this burden estimate or any other aspect of this collection of information,

including suggestions for reducing this burden, to Washington Headquarters Services, Directorate for Information Operations and Reports, 1215 Jefferson Davis Highway, Suite 1204, Arlington

VA 22202-4302. Respondents should be aware that notwithstanding any other provision of law, no person shall be subject to a penalty for failing to comply with a collection of information if it

does not display a currently valid OMB control number.

1. REPORT DATE

30 SEP 2007

3. DATES COVERED

4. TITLE AND SUBTITLE

Finescale Planktonic Vertical Structure: Horizontal Extent And The Controlling Physical Processes Layered Organization In The Coastal Ocean (LOCO) DRI

2. REPORT TYPE
e: Horizontal Extent And The
Organization In The Coastal

6. AUTHOR(S)

7. PERFORMING ORGANIZATION NAME(S) AND ADDRESS(ES)

Oregon State University, College of Oceanic and Atmospheric Sciences,104 Oceanography Admin Bldg,Corvallis,OR,97331

9. SPONSORING/MONITORING AGENCY NAME(S) AND ADDRESS(ES)

5a. CONTRACT NUMBER

5b. GRANT NUMBER

5c. PROGRAM ELEMENT NUMBER

5d. PROJECT NUMBER

5e. TASK NUMBER

5f. WORK UNIT NUMBER

8. PERFORMING ORGANIZATION

REPORT NUMBER

10. SPONSOR/MONITOR'S ACRONYM(S)

11. SPONSOR/MONITOR'S REPORT $\operatorname{NUMBER}(\mathrm{S})$

12. DISTRIBUTION/AVAILABILITY STATEMENT

Approved for public release; distribution unlimited.

13. SUPPLEMENTARY NOTES

The original document contains color images.

14. ABSTRACT

15. SUBJECT TERMS

16. SECURITY CLASSIFICATION OF:

a. REPORT

unclassified b. ABSTRACT

unclassified c. THIS PAGE

unclassified
17. LIMITATION OF ABSTRACT
18. NUMBER

OF PAGES

7 19a. NAME OF

RESPONSIBLE PERSON 
fluorometers, acoustic Doppler velocimeter (ADV), acoustic Doppler current profiler (ADCP)) to obtain centimeter-scale resolution of hydrographic and bio-optical properties.

It was critical to our objectives to resolve the vertical gradients in the horizontal velocity field. Previous work has shown (Cowles, 2004) that thin planktonic layers are closely associated with sharp vertical gradients in velocity within narrow bands of stratification. We found that conventional ADCP measurements over $4 \mathrm{~m}$ depth bins cannot resolve the vertical shear that appears to form and maintain thin layers. Therefore, we used a $600 \mathrm{kHz}$ ADCP mounted $1.5 \mathrm{~m}$ below the ocean surface on a vertical pole off the port side of the $R V$ New Horizon (2005) and the $R V$ Thompson (2006). In addition, we mounted a second ADCP on our profiling system, although we used a $1 \mathrm{MHz}$ Nortek Aquadopp in 2006 instead of the $600 \mathrm{MHz}$ system used in 2005. The combined boom-mounted ADCP system and profiler-mounted ADV and ADCP systems have provided us with velocity gradients on vertical scales relevant to the biological structure.

From a programmatic standpoint, the fieldwork in 2005 and 2006 on the survey vessel was tightly integrated with the broad science objectives of LOCO. In both 2005 and 2006, LIDAR maps (B. Concannon and J. Prentice) and bio-acoustic maps (K. Benoit-Bird) overlap all of the high-resolution ADCP surveys as well as the vertical profiling work. Continuous cross-isobath glider tracks in 2006 (D. Fratantoni) provided essential time series data on the spatial structure of the northern portion of the Bay while we were obtaining vertical profile data in other portions of the Bay. In addition, the glider tracks functioned to extend the mooring array "line" out into our survey domain. Based on the clear need for additional direct sampling of zooplankton outside the mooring array, numerous vertical profiles of zooplankton abundance and composition were obtained with a pumping system (M. Sutor), while over 100,000 high-resolution optical images of zooplankton were obtained with a new CCD camera system (M. Sutor). These complementary projects will enhance the interpretation of our vertical profile and ADCP results.

The analysis of wind-driven and tidally-driven vertical mixing, in the context of layer persistence, is now the major task before us. We expect to report on some of these analyses at the LOCO workshop in Orlando in 2008, and at the 2008 Ocean Sciences Meeting.

\section{WORK COMPLETED}

During FY2007 we completed final data quality and calibration checks on all the hydrographic and bio-optical data obtained during the 2005 RV New Horizon cruise and the 2006 RV TG Thompson cruise. Plots of all 1400 high-resolution vertical profiles obtained during the LOCO field experiments have been posted on our project website (http://argon.coas.oregonstate.edu/biooptics/projects.htm) and the data are available to all LOCO investigators.

We have completed preliminary maps of the horizontal extent and temporal persistence of planktonic thin layers observed in both 2005 and 2006. We are using these preliminary maps to identify regions of the study domain that contain more/fewer layers than other regions of Monterey Bay. The outcome of this analysis will lead to a comparison with the LIDAR and bio-acoustic maps being generated by other LOCO PIs. We will present the results of this analysis at the 2008 Ocean Sciences Meeting in Orlando. 
We have completed the preliminary, interannual comparison of vertical gradients in particulate properties (using bio-optical fluorescence, spectral absorption, and spectral attenuation) and the gradients in dissolved organic material (using CDOM fluorescence) in relation to the local velocity gradients. As described below, this analysis reinforces the earlier observations that velocity gradients in coastal waters are vertically constrained, but also illustrates the use of optical properties as a signature of recent biological/chemical history of a local water mass.

We have completed an analysis of the cross-isobath differences in water column vertical structure between the depth range of the mooring array $(\sim 20 \mathrm{~m})$ and slightly deeper regions of the bay. This analysis is based on repeated high-resolution horizontal sections between the $20 \mathrm{~m}$ and $45 \mathrm{~m}$ isobaths during the July 2006 fieldwork. During each cross-shelf section, successive vertical profiles were less than $250 \mathrm{~m}$ apart. This analysis supports the observation that inner shelf $(<25 \mathrm{~m})$ conditions, as measured at the mooring array, were often distinct from those observed beyond the $25-30 \mathrm{~m}$ isobath.

As in 2005, all of our vertical profiles were obtained while the LIDAR system of Concannon and Prentice was operating, and while the bio-acoustics array of Benoit-Bird was operating. Our analyses during the coming year will focus on cross-calibrations of these different layer detection systems during the 2005 and 2006 field experiments.

\section{RESULTS}

As documented in the FY2006 Annual Report, in both 2005 and 2006 we observed thin layers of biooptical properties in Monterey Bay in association with steep vertical gradients in physical properties, including the horizontal velocity structure. It is important to note, however, that numerous contrasts in layer structure and occurrence existed between the 2005 and 2006 field years. Those contrasts will become more apparent as all the LOCO investigators complete their respective analyses and interpretations. From our data obtained via high-resolution profiling, we can assert that a consistent relationship does exist between the vertical structure of the velocity field and the vertical patterns of optical properties. By comparing our findings with the bi-acoustic observations of Dr. Benoit-Bird, we have found that the optical expression of the plankton layers was often strongly linked to the bioacoustical structure of the water column (Figure 1), and both appear related to the local velocity gradients. Note that the acoustic record reveals clear signatures of high-frequency internal waves, with some evidence of breaking internal waves within the upper 10m (near 9min mark of panel 2, Fig. 1). Note also in the lower panel of Figure 1 that the plankton thin layer (chl) at $13 \mathrm{~m}$ was just above a high shear layer, while the small chl feature at $8 \mathrm{~m}$ was just below a shear layer. This type of correlation between shear and persistent plankton layers was common during both field years.

Another important analysis this year has been the documentation of the value of the profiles of chromophoric dissolved materials. We have found that the vertical gradients of fluorescent CDOM often reveal aspects of the physical structure not apparent in the vertical profiles of particulate material. For example, we often see subsurface intervals of distinct CDOM fluorescence associated with salinity intrusions (Figure 2). This figure also illustrates that "thin layers" can reflect local minima in concentration, while the association between velocity gradients and concentration gradients remains high. The distinct vertical separation between portions of the CDOM concentration profile suggests that these local water masses possess a temporal tag of biological or chemical conditioning. We will be examining this potential "time tag" in more detail during the coming year of analysis. 

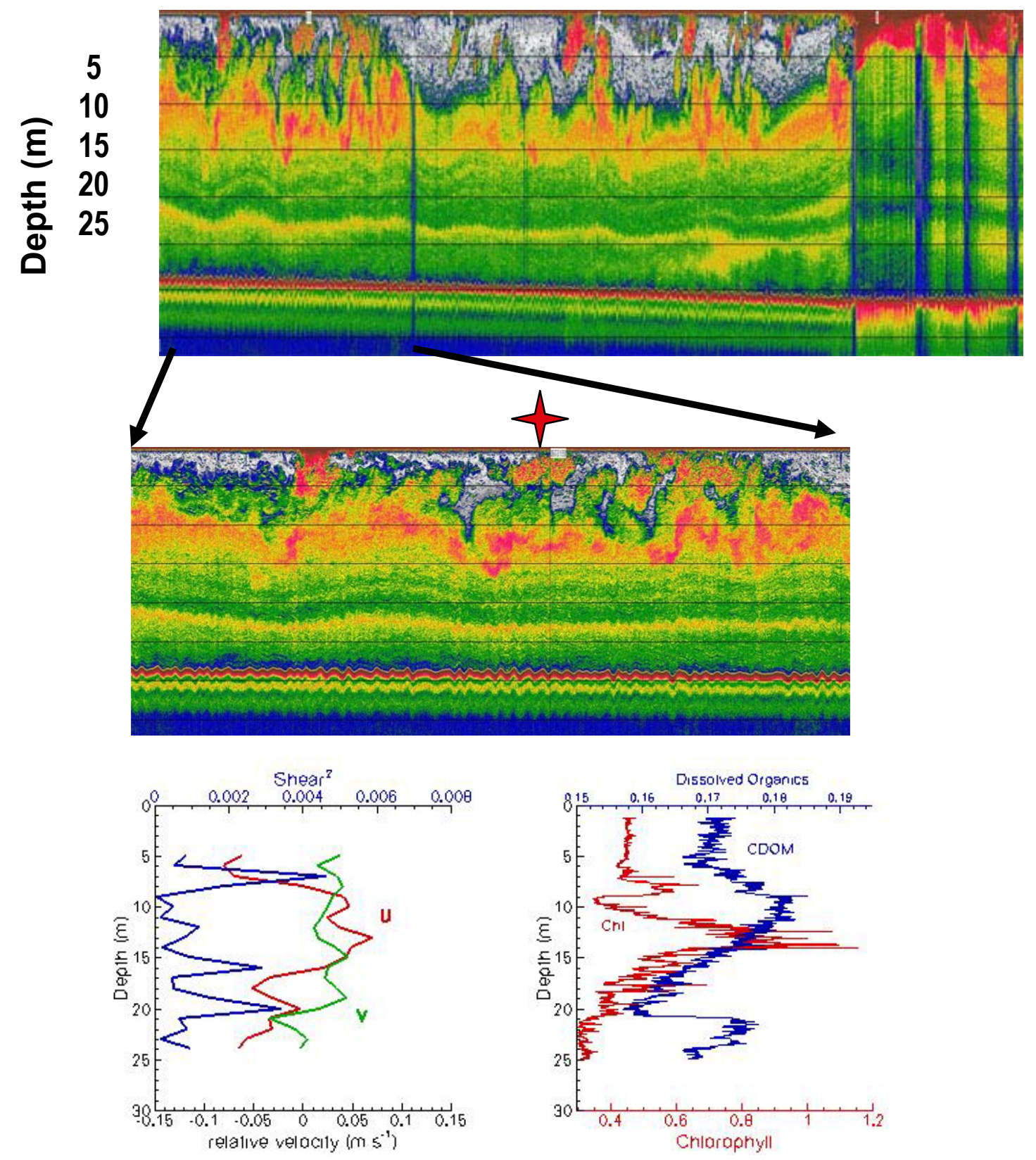

Figure 1. The upper panel displays 30 mins of $120 \mathrm{kHz}$ acoustics within a $30 \mathrm{~m}$ deep water column in Monterey Bay. The acoustic gradients define the high-frequency (5-10min period) internal waves that were present throughout the shallow water column. The middle panel shows the first 10 mins of the data record from panel 1, while the lower double panel shows an individual free-fall profile of chlorophyll and CDOM fluorescence (at 6 min mark, marked by red star) with the coincident vertical structure of the horizontal velocity field (shear in blue, $u$ in red, $v$ in green). 



Figure 2. Vertical profiles of density, chlorophyll (mg $\left.\mathrm{m}^{-3}\right)$, and CDOM (volts) on successive days in Monterey Bay in July 2006. Panel (A) shows the distinct chlorophyll and CDOM maxima in a thin layer between 8-10m depth, with little chlorphyll structure deeper than 10m. In contrast, panel (B) reveals several steep vertical gradients and thin layers of CDOM fluorescence, with the deepest minimum layer of CDOM occurring where only a small peak of chlorophyll fluorescence was found.

\section{IMPACT/APPLICATION}

Our results from prior studies of planktonic thin layers suggest that the analysis and interpretation of the LOCO field experiments will substantially enhance our understanding of bio/physical interactions in general, and thin layers in particular. We anticipate that the results will have broad application in ocean ecology.

\section{TRANSITIONS}

The results of the LOCO fieldwork will provide new insights into the mechanisms that create that persistent pattern on small-scales, particularly over horizontal scales of many 10 s of kilometers. Continued evaluation of these mechanisms will be essential for prediction of the impact of persistent small-scale pattern on the attenuation of optical and acoustic signals in the upper ocean. Observational techniques employing autonomous vehicles and profiling systems may now be applied at various oceanic study sites, thus extending our appreciation of the role that small-scale processes may play in our estimates of water column production. 


\section{RELATED PROJECTS}

We have active collaborations with the following ONR Principal Investigators:

Dr. Kelly Benoit-Bird, Oregon State University

Dr. Percy Donaghay, University of Rhode Island

Dr. Jan Rines, University of Rhode Island

Dr. Dave Fratantoni, Woods Hole Oceanographic Institution

Dr. Margaret McManus, University of Hawaii

Dr. Jennifer Prentice, NAVAIR

Mr. Brian Concannon, NAVAIR

Dr. Van Holliday, University of Rhode Island

Dr. Malinda Sutor, LSU and WHOI

\section{REFERENCES}

Cowles, T.J. 2004. Thin layers of plankton: physical and biological interactions on the small scale. In: Handbook of Scaling Methods in Aquatic Science, L. Seuront and P. Strutton, editors, CRC Press, Boca Raton, FL., USA, pp. 31-49.

\section{PUBLICATIONS (refereed)}

Cowles, T.J. 2004. Thin layers of plankton: physical and biological interactions on the small scale. In: Handbook of Scaling Methods in Aquatic Science, L. Seuront and P. Strutton, editors, CRC Press, Boca Raton, FL., USA, pp. 31-49.

Alldredge, A.L, Cowles, T.J., MacIntyre, S., Rines, J.E.B., Donaghay, P.L., Greenlaw, C.F., Holliday, D.V., Dekshenieks, M.M., Sullivan, J.M., and Zaneveld, J.R.V. 2002. Occurrence and mechanisms of formation of a dramatic thin layer of marine snow in a shallow Pacific fjord. Mar. Ecol. Prog. Ser., 233: $1-12$

Eisner, L.B., Twardowski, M.S., Cowles, T.J, and Perry, M.J. 2003. Relationship between phytoplankton pigment concentration and in situ spectral absorption measurements in East Sound, Orcas Island, Washington. Limnol. Oceanogr., 48: 632-646.

McManus, M. et al. 2003. Characteristics, distribution and persistence of thin layers over a 48 hour period. Mar. Ecol. Prog. Ser., 261: 1-19. 